\title{
How Can Platform Leader Achieve Sustainable Development in Platform-Based Ecosystem?
}

\author{
Yi Zhang1, Haiquan Chen ${ }^{2}$ \\ ${ }^{1}$ School of Business Administration, Guangdong University of Finance, Guangzhou, China \\ ${ }^{2}$ School of Management, Jinan University, Guangzhou, China \\ Email: zhangyisg@126.com, *jnuchen@qq.com
}

How to cite this paper: Zhang, Y., \& Chen, H. Q. (2020). How Can Platform Leader Achieve Sustainable Development in Platform-Based Ecosystem? Modern Economy, 11, 1476-1496. https://doi.org/10.4236/me.2020.118105

Received: July 7, 2020

Accepted: August 28, 2020

Published: August 31, 2020

Copyright $\odot 2020$ by author(s) and Scientific Research Publishing Inc. This work is licensed under the Creative Commons Attribution International License (CC BY 4.0).

http://creativecommons.org/licenses/by/4.0/

(c) (i) Open Access

\begin{abstract}
Commercial competition paradigm is changing from competitive advantage which based internal resources to the eco-advantage which from ecosystem consisted of internal and external value network under the background of the Internet economy. Enterprises can't effectively face the complex and fierce market competition environment which relied solely on internal heterogeneous resources or core competencies, so many firms adopt platform strategy and build a business ecosystem to be out of this dilemma. It could get eco-advantage for platform leaders to leverage the external resources and ability from the business ecosystem. How can platform leaders gain sustainable development depending on the superiority niche in the platform ecosystem? This paper will answer this question by taking JD as an example which is a typical B2C Internet platform. The results of the study are as follows: First, the platform firm is the leader and creator in the early establishment of the platform-based ecosystem, it's the formational basis of eco-advantages comes from enough quantity and high quality of platform user. User install and demand are not only the important orientations for platform enterprises producing and managing but also the power source for forming eco-advantages and sustainable development. Second, the sustainable development of the platform leader is related to the size and strength of the network effect. The more network effects, the more conducive to get eco-advantages and sustainable development for platform leaders. Third, the platform-based ecosystem is a value network consisted of a large number of network nodes which is a symbiosis relationship by competing and cooperating. The cross-border integration and collaborative development of multi-agent in the ecosystem are beneficial to promoting platform leaders to form ecological advantages and achieve sustainable development. Forth, platform leader, which is the leading species and key species determined the fate of species in the ecosystem, provides a place for value co-creation of multi-species. It is the process of multi-agent value co-creation based on the platform for platform leaders to ob-
\end{abstract}


tain sustainable development, which is also the result of internal innovation and external open innovation. This study is of great significance to enrich the research of platform enterprise theory and guide the sustainable development of platform enterprise.

\section{Keywords}

Platform Leader, Platform-Based Ecosystem, Sustainable Development, Reciprocity, Value Co-Creation, Eco-Advantage

\section{Introduction}

More and more enterprises achieved rapid growth through made platform strategy and built a business ecosystem in the last ten years (Gawer \& Cusumano, 2014; McIntyre \& Srinivasan, 2017), such as Tencent, Alibaba, JD, Baidu, Suning, Shanda, Amazon, Facebook, Google, Microsoft, YAHOO, eBay, Apple and so on. Why so many companies try to carry out platform transformation and build a business ecosystem to achieve sustainable development?

Enterprises face more complex competition with information and communication technology (ICT) development. The paradigm is no longer among individual enterprise but turns into a competition between the ecosystem based on the platform leader enterprise (Kale et al., 2002; Bouncken \& Fredrich, 2016). It is difficult for a single enterprise to achieve sustainable development by its resources and capabilities when faced with the dynamics, complexity, and uncertainty competitive environment. Enterprises had to take ecosystem strategy, not only take advantage of their power but also rely on the external resources and capabilities to overcome the uncertainty and reduce transaction costs (Boudreau \& Jeppesen, 2015; Adner, 2017).

The ecosystem derived from biology and had been applied to business research since the commercial ecosystem proposed by James Moore in 1993 (Moore, 1993). The platform-based ecosystem, which constructed by the platform leader and consisted of many complementary, is an economic organization that firms could get synergy effects, cooperation, and sharing resources (Adner, 2017). The business ecosystem strategy is the revolution and redefinition of competitive strategy, it emphasizing multidimensional characteristics of competition (Bengtsson \& Kock, 1999). The eco-advantages of platform enterprises in the business ecosystem are different from traditional competitive advantage. The business ecosystem emphasizes to construct value platform that could leverage other related firms' resources and capabilities, creates a dynamic structure composed of business activities and assistant service system, and optimize the enterprise internal and external resources and abilities to achieve cross-border competition and integration (Makadok, 2001; Vargo et al., 2008).

Platform ecosystem is the business ecosystem based on the platform leader, and platform leader is the core enterprise in this system, which connects the 
supply sides, demand sides and the third-parties in the multilateral market (McIntyre \& Srinivasan, 2017). Platform leader is the key component of the ecosystem and also is the value platform of the whole network (Bellamy, Ghosh, \& Hora, 2014). What are the eco-advantages and how to form the platform leader in the ecosystem? How can platform leaders achieve sustainable development in the platform ecosystem? How to explain the mechanism of platform leading enterprises to achieve sustainable development in the platform ecosystem? Therefore, this study attempts to make an exploratory study on how platform leaders achieve sustainable development in the platform ecosystem.

It is of great theoretical significance and practical value to explore the approaches and mechanisms of sustainable development of platform leader in the platform ecosystem. The platform leader is the leader of the platform ecosystem. The relationship between platform leader and platform ecosystem is that both sides lose and prosper. Platform leaders can't achieve sustainable development without the support of the platform ecosystem. This research will reveal the formation process of the platform ecosystem and help enterprises to transform and upgrade by ecology strategy. It also facilitates the growth and construction ecosystem for the leader, optimizes the resources and abilities, and gets a long time competitive advantage in the market. Therefore, this paper will research the way and mechanism of platform leader firm to achieve sustainable development, and explore the formation mechanism of the platform ecosystem, using the case study method, selecting the typical enterprise as the research object.

\section{Research Design}

\subsection{Research Method}

The purpose of this paper is to explore the way and mechanism of sustainable development of platform leading enterprises in the evolution process of the platform ecosystem, so we adopt case study method which was a useful qualitative research method that could better answer "why" and "how" compared to quantitative research (Yin, 2009). The research question of this paper is that how can platform leaders achieve sustainable development in the platform ecosystem? And what is the path and mechanism of its formation? Therefore, the case study method is appropriate for this study (Eisenhardt, 1989). It conducted deductive theoretical development based on the JD group according to the recommendations of Sigglkow and Van de Ven (Siggelkow, 2007; Van de Ven, 2007). This paper used a single case to explain general principles from longitudinal development of the ecosystem to ensure the depth, typicality, and validity.

\subsection{Research Sample}

JD was selected as the case study in this paper, and taken the ecosystem constructed by JD as an analysis unit. The development process of JD was divided by several important strategic transformations and ecosystem evolution characteristics through repeated comparison and summary, and finally, summarize the 
key behaviors that can be copied in different stages of development. JD is the largest (revenue and size) B2C Internet platform firm China, and is the global top 500 enterprises according to "Fortune" in 2016 and 2017'. JD is not only an e-commerce enterprise that China's firm first successful listing in the NASDAQ, but also the world's top ten internet companies. More than 40 million goods, including appliances, mobile phones, computers, mother and baby, clothing, and so on, and a lot number of enterprises in the JD e-commerce platform. At the same time, JD developed a financial and logistics supporting system, constructed a complex demand-oriented business ecosystem to collaborate with other enterprises. JD has achieved good operational results by ecosystem strategy, which is a typical case for ecosystem studies.

\subsection{Data Collection and Research Steps}

The data in this paper are mainly from the public of the company, including the annual report, events, important leadership speech and interview reports, books, research papers related the JD. We tracked observe JD for a long time (from September 2005 to now) to ensure the data get the triangle verification requirements, and each element in the framework of the theory has been repeated support. We will refine the behavior in the process of JD ecosystem evolution, explain the facts that forming path and mechanism, explore the path and mechanism of sustainable development of platform leading enterprises in platform ecosystem by analyzing the key events, decision-making, and activities in different stages, multi-sides platform, evolution characteristics of JD and the development of the business ecosystem.

\section{Case Description}

\subsection{Background}

JD was founded in 1998, initially only sold magneto-optical products as a broker. The company rapidly developed and diversified as many strategic acquisitions and mergers in the next nearly twenty years, and the large group consists of two subgroups (including JD mall group, financial group), a subsidiary (PAT), and the overseas department. In May 2014, JD is on the United States Nasdaq Stock Exchange-listed. Nowadays, JD has developed into an integrated Internet platform enterprise with three major business segments, including e-commerce, finance, and logistics. JD gradually opened up its ecosystem and a large number of third-party joined in the platform from the early closed-loop mode, and the ecosystem has been gradually improved, the eco-advantage has begun to appear.

\subsection{Development Stages and Key Behaviors of JD}

The development process of JD was classified as an establishment, transition, expansion, maturity period according to its pivotal development. And now JD is in the maturity period.

${ }^{\text {lhttps://about.jd.com/honors/. }}$ 


\subsubsection{Establishment Period (June 1998 to December 2003)}

JD was a broker in the ecosystem at the establishment stage. JD was founded in Beijing by CEO Liu Qiangdong on June 18, 1998. The firm mainly engaged in the field of magneto-optical, it played a sale agents role, then built thousands of stores off-line during the next few years, and had become the most influential domestic middlemen sold magneto-optical products. The brand "JD" can be formally put forward in this period, but the business model is different from that of the latter. The profit mainly came from the price scissors between product purchase and sale. But the SARS had a serious impact on the social and economic in China during this period, the sale of the store was greatly impacted, so paved the way for the next phase of transition.

\subsubsection{Transition Period (January 2004 to May 2007)}

JD was an opportunity discoverer in the ecosystem at the transition stage. In January 2004, JD developed the e-commerce model, JD multimedia network opened to the customers. JD's turn to online from offline had set up subsidiaries in Shanghai and Guangzhou. JD engaged in Internet and backstage facilities construction, development of the supply market that constantly absorbing sellers and well-known brand into the platform, expanding and strengthening the influence of supply to ensure the quality of the goods, attract consumers purchasing in the platform by publicity and advertisement. This strategic transition was the most important step for the development of JD, JD has become one of the earliest enterprises which develop e-commerce business in China. This stage is the embryonic stage of JD's ecosystem construction.

\subsubsection{Expansion Period (June 2007 to February 2013)}

JD was edificators in the ecosystem at the expansion stage. In June 2007, JD had changed its name to JD Mall and the strategic positioning located in the domestic B2C market. First, it had built logistics systems in Beijing, Shanghai, Guangzhou, and other cities, established the package tracking system (GIS), provided the support system for the rapid development of e-commerce, and developed western markets by building an English website. Second, it got the capital assistance from many international well-known enterprises and celebrities, such as Capital Today, Bull Capital Partners, DST, Tiger Fund, Kingdom Holding Company (KHC), Ontario Teachers' Pension Plan, Liang Botao and so on, depending on its good business model and development prospect. Third, JD Mall constantly enriched the types of products and services, entry into the market for example 3C, medicine, books, electronic publications, hotel reservation, luxury, and Japan and South Korea market. Forth, it activated the direct network effect by attracting high-quality suppliers getting into the platform and providing the best products and services for customers. Fifth, JD continuously improve the quality of service to create a good experience for customers, such as providing on-site service, carrying out mobile POS credit card for consumption service, opening the pick-up service, exploration $\mathrm{B} 2 \mathrm{C}$ value-added service, attention af- 
ter-sales service, providing GIS package tracking service, at the same time, continue to improve the capability of goods selling and order processing. Sixth, JD uses APP, sales platform, and intelligent mobile phone and computer software to start up the mobile Internet strategy to constantly attract a large number of users to register in the platform by group purchase and other promotions activities. Last, JD Mall provided JOS on the line, marking the opening of the JD Mall. At this period, the direct and indirect network effect has been activated and initially formed a JD integrated retail online shopping platform, the basic structure including platform, content, technology, and application has been established and developed new overall service standards of the e-commerce industry. The general framework of the JD Internet platform and business ecosystem has been formed, the contents were constantly enriched and operating mechanisms were improved.

\subsubsection{Maturity Period (March 2013 to Now)}

JD was a keystone species of the ecosystem at the Maturity stage. First, JD had been changed its name second times and replaced the LOGO, became more diverse and varied, updated the enterprise brand and image on March 30, 2013. Second, JD had been adjusted their strategy to develop e-commerce, finance, and logistics module, build subgroup of logistics, financial group, JD Mall group, pat Network, and overseas business department, get in-depth cooperation with the Tencent, Yonghui supermarket, WAL-MART, and other large and powerful enterprises, invest in some vital areas, cooperate with the international well-known brand. Third, the organizational structure and original marketing distribution system had been a major revision. It divided into four modules, including $3 \mathrm{C}$, household appliances, consumer goods, and home furnishing according to the strategy of the group. Forth, the types of products and services had been rich, for example, provided micro-credit loans, flowing loans, guaranteed loans, cash, financing for receivable accounts, domestic and foreign insurance, and financial services for POP sellers on the platform. The platform which engaged in combined shopping with social interaction and registered users exceeded 100 million provided basic communication, logistics infrastructure, and customized services for users. Fifth, there were some business model innovations in the JD platform. JD continued to innovate in procurement, $\mathrm{O} 2 \mathrm{O}$, finance, information technology, to be providers of community infrastructure in China. The co-operational mode and strategic of mutual priority, mutual benefit, and win-win had been put forward. JD provided bonuses supporting e-commerce participants in the ecosystem to promote the growth of the B2C ecosystem and get collaborative development and win-win cooperation. JD listed on the NASDAQ (Stock Code: JD) on May 22, 2014, and became China's largest listed company in the United States IPO. Overall, JD had implemented the diversification strategy, constantly enriched the content of products and services, absorbed plenty of sellers and users to activate the network effect, and constructed a business ecosystem that was mature, symbiotic and sharing at this period. 


\section{Case Analysis and Discovery}

The role of JD has changed from middlemen to key species in the business ecosystem. Why does JD want to develop a platform and continue to expand the ecosystem? What does sustainable development depend on when it becomes a leader in the ecosystem? How to use platform functions to obtain external capabilities and resources? And how to achieve sustainable development through the platform ecosystem? This paper will analyze the development process of JD and explore the path and mechanism of the platform leader to achieve sustainable development. Therefore, this paper proposes a conceptual model of platform leader sustainable development in the platform ecosystem (Figure 1).

The advantage of platform leader not only comes from the core competitiveness which relied upon itself internal heterogeneous resources and abilities but also comes from the ecosystem which based on the integration of internal and external resources and capabilities (Wernerfelt, 1984; Makadok, 2001). JD has gone through four stages of development, and it can be seen from Table 1 that

Table 1. Competitive characteristics of JD at different development stages.

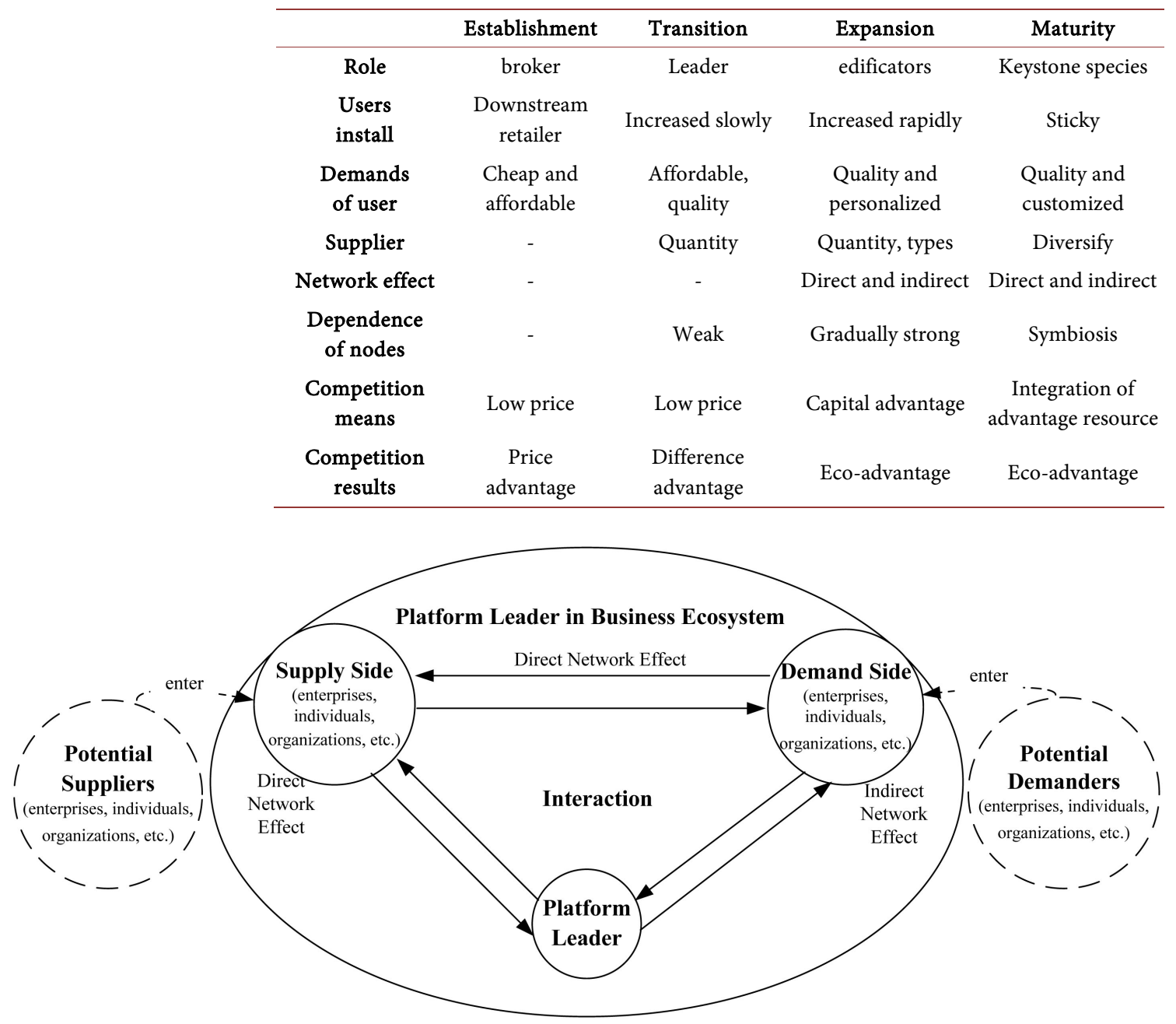

Figure 1. A conceptual model for platform leader in B2C business ecosystem. 
the competitive characteristics of JD are changed in different development stages. In the early days, the competitive advantages of JD mainly come from the scissor's difference between the purchase and sale of the commodities, so this was a cost advantage of a traditional business model that can easily be imitated, replaced, and lost the advantage by a competitor. JD seized an opportunity of developing e-commerce and provided a large number of good quality products and services to get differentiated competitive advantages through strategic transformation. In rapid expansion and mature period, JD attracted a lot of suppliers which provided products and services by the control of quality and provided customized and personalized services. At the same time, attracted a large number of customers, stimulated the direct and indirect network effect, to attract more consumers and third-party sellers registering in the platform, enhanced the interdependence between the enterprises and the consumers, enterprises, and enterprises, consumers and consumers, and formed a network which integrates the advantages, resources and capabilities to form eco-advantages between each node in the ecosystem.

It found that the sustainable development of platform leadership in platform ecosystem mainly comes from four aspects through the decomposition of strategies and actions about JD evolution: driven of user base and user demands, the excitation of the network effect, coopetition and symbiosis of node enterprises in the ecosystem, value co-creation based on a platform for enterprises and customers.

\subsection{User Base and Consumer Demand}

The user base, which was the basis of the platform and business ecosystem, affects the strategic choice of the leading firm (McIntyre \& Srinivasan, 2017). The model of enterprise-centered and supply-oriented had been replaced by one of user-centered and demand-oriented, and enterprises must adjust the management in the Internet era (Adner, 2017; Boudreau \& Jeppesen, 2015). The value creation activities of all species in the platform business ecosystem should be based on user demands (Bellamy, Ghosh, \& Hora, 2014), pay attention to the user experience, and enhance the perceived value for users through the co-creation to create eco-advantages (Bouncken \& Fredrich, 2016).

The user base includes two aspects: number and quality. Population ecology theory holds that forming cluster effects need several species in the platform ecosystem (Hannan \& Freeman, 1977). If each enterprise or individual is considered as a species, the formation of the ecosystem requires the existence of a variety of species at the same time, and the number of species must reach the minimum threshold. Platform users which were the most important species in the ecosystem include demand sides and supply sides (Zhu \& Iansiti, 2012). Demand sides can be subdivided into individual consumers, enterprises, end-users, and so on. The supply sides included producers, manufacturers, suppliers, developers, third-party supplements, and so on. The number of users is a 
necessary condition for platform ecosystem construction and stimulation of the network effect (Boudreau \& Jeppesen, 2015). The activation of the direct network effect needed some same types of users, forming indirect network effects also need to meet the minimum number of bilateral users (Gawer \& Cusumano, 2014).

User quality is critical to the long-term development of the ecosystem. Those firms who want entry into the platform ecosystem must comply with the platform rules, requirements, and standards. Activation, heterogeneity, and diversity were the feature of users (McIntyre \& Srinivasan, 2017; Boudreau \& Jeppesen, 2015). The online users who were the real user of the platform could be considered as ecological species, and their superior resources and capabilities can be controlled, reconfigured, and used by the leader enterprise (Boudreau \& Jeppesen, 2015). Heterogeneity and diversity of ecosystem species can promote the producers to provide diversified products and services, meet energy exchange and material circulation between different species, contribute to the sustainable development of platform leader's eco-advantages by this virtuous cycle, enrich the species types, vitality and competitive strength of ecosystem (Hannan \& Freeman, 1997).

User demand is an important direction for enterprises in the ecosystem to produce and provide services. Satisfying customer demand is the foothold of enterprises in producing and operating activities and providing services (Adner, 2002). Those products and services provided by enterprises can only meet the needs of users to maintain the sustainable development of enterprises (Benson et al., 2016). Enterprises that do not meet customer needs can't achieve their economic goals. Customer demand is the driving force for enterprises to the product, and also the motion for leader enterprise to construct eco-advantages and maintain sustainable development (Zhu \& Iansiti, 2012).

In the JD platform business ecosystem, the user base and generated demand were the basis of the survival and development of the B2C platform. JD was an e-commerce platform that provides the infrastructure and services for the supply and demand side. The basis of existence and development for this platform was to own some users and their demands. Both sides of supply and demand could create and exchange value relied on information, capital, logistics, customer service, and other services providing by JD. After JD transferred its strategy to e-commerce, it had continuously enriched and improved its products and services according to the needs of users. The needs of users were constantly changing. The customers initially only paid attention to the price that could be cheap and affordable, but emphasized quality, personalized, and customized with the increase in consumer demand. So it required JD not only to pay attention to quality and quantity but also to provide personalized products and services. JD as an e-commerce firm that doesn't have its manufacture, prompted JD to become the platform and build a business ecosystem to satisfy the consumer's demands. It required that many different types and functions of enterprises which provided their resources and ability to create value for customers to join in the 
ecosystem, to meet customer demand by matching the supply and demand. JD platform provided more than 40 million kinds of goods including 13 categories, involving tens of thousands of enterprises. Those enterprises and millions of online consumers together contributed to the forming of eco-advantages through co-value creation.

Overall, the ecosystem constructed by JD which located in the core niche. JD insisted on that enrich the user experience by the interaction of species in the ecosystem driven by demand, timely captured and feedback the demand behavior by the background data processing system and information technology, dynamically adjusted commodities, and timely delivery demand information to the supplier.

Proposition 1: Platform leader was the edificators at the establishment stage of the ecosystem. Larger numbers and higher quality platform users were the foundation to build the ecosystem and form eco-advantages. User demands were an important direction for enterprise production and operation, also the power source of sustainable development for platform leader.

\subsection{Network Effect}

The scale and intensity of network effect were closely related to the competition of the ecosystem and the sustainable development of platform leaders. The network effect was divided into direct network effects and indirect network effects (some scholars called same-side network effects and cross-side network effects) (McIntyre \& Srinivasan, 2017; Boudreau \& Jeppesen, 2015). The direct network effect will lead to scale growth of the same-side of the user (supply or demand side), the indirect network effect will promote the growth of another side (Eisenmann, Parker, \& Van Alstyne, 2011; Boudreau \& Jeppesen, 2015), for example, the number of the increase of suppliers will attract the demand side, and the demand side will drive the increase of the supply side. There is no network effect in the initial stage of platform ecosystem development, and free or preferential strategies are often adopted to be attracted, early entrants. The platform enterprises can attract more users through high-quality users which including high-quality suppliers demanders (Boudreau \& Jeppesen, 2015). The quality can not only promote the increase in the number of same-side users but also will advance the another-side user expansion. The network effect can be activated when the number of platform users reached the minimum threshold. Then the direct and indirect network effect played the function at the same time, the number of users will grow exponentially, so consumers can be obtained directly welfare from the network effects with more consumer purchasing, also obtain complementary products and services from the indirect network effect (McIntyre \& Srinivasan, 2017; Boudreau \& Jeppesen, 2015). The scale and intensity of network effects were critical to the network control ability, ecosystem-scale, and competitiveness of platform enterprises (Benson, Gleich, \& Leskovec, 2016). The scale and intensity of the network effects are positively related to the eco-advantages of the leader enterprises. The stronger the network effect, the stronger the ability 
of the platform enterprise. The more the external resources can be leveraging and utilized by the leading enterprise, the more obvious the eco-advantages (Grant, 1991), and the more conducive to the sustainable development of platform leader.

The stimulation of the JD platform leader network effect leads to the formation of ecological advantages. The network effect is not formed in the early stage of JD development, it is necessary to use some measures to attract the user's entry to expand the base by preferential price or free activities to attract high-quality sellers to enter, to attract more sellers to enter the platform, brought about enterprise agglomeration; and attract consumers enter the platform through the promotion and free registration. The network effect would be activated when the number of buyers and sellers breakthrough threshold, more and more firms would join the platform because huge consumer demands on the JD platform, more consumers were willing to join the JD on the platform as provided diversified products and services on JD platform. Thus the network effects play an important role leading to more and more high-quality suppliers and demanders join the JD platform and promoting the network effect more and more powerful. Network effects brought the scale increasingly larger, rapid expansion of platform ecosystem, more and more external resources could be controlled and utilize by JD platform as the leader, so the eco-advantages will be more obvious, and was beneficial to achieve sustainable development for platform leader.

Proposition 2: the scale and intensity of network effects were critical to the eco-advantages. The stronger network effects lead to more obvious eco-advantages and were beneficial to achieve sustainable development for platform leaders.

\subsection{Competition and Dependence Symbiosis of Multi-Species}

Cooperation mechanism exist simultaneously in the ecosystem (Bengtsson \& Kock, 1999; Enkel \& Heil, 2014), it promoted the survival of the fittest among the ecological species, which were important mechanisms for the formation of eco-advantages and promoting the evolution of the ecosystem, it was also an important way to realize sustainable development for platform ecosystem (Gawer \& Cusumano, 2014). Homogeneous enterprises will compete when they provided the same services and products for customers. Heterogeneous enterprises were cooperation and complementarity relationship to provide different services and products for diversified demands consumers, so most of them adopt the win-win cooperation strategy (Falk \& Fischbacher, 2006). The cooperation mechanism provides a clue for the win-win of enterprises and integrations of the advantageous resources. Cooperation and competition together promoted the development of the ecosystem (Bouncken \& Fredrich, 2016), and achieve sustainable development for platform leader enterprises.

Cooperation mechanism is beneficial to integrate the superiority resources provide products and services for consumers with many complementary through value creation activities in the ecosystem. Cooperation contributes to the en- 
hancement of value creation and facilitates reciprocal forming among species (Falk \& Fischbacher, 2006; Barve et al., 2001). It is difficult for enterprises to win by themselves in the Internet era. Enterprises had to cooperate to overcome their limitations to get sustainable development (Bengtsson \& Kock, 1999). The formation of the JD ecosystem can't be separated from the cooperation of various types and different functions of enterprises.

The JD not only cooperated with well-known brands which in domestic and international, but large enterprises, also cooperation with cross-industry and regional, for example also cooperated with electronic products, medicines, books, hotels, cooperation with small and medium-sized enterprises. JD had constantly enriched the products and services to meet consumer multi-level and diversified demands. The eco-advantages of leader enterprises were constantly increasing with the enrichment of products and services in the ecosystem.

Competition mechanism is conducive to upgrading the quality of products and services. The species without competition have no vitality and vitality by the principle of survival of the fittest, and species may be eliminated or eliminated by other ecosystems (Bengtsson \& Kock, 1999). There was fire completion among homogeneous enterprises, products, and services. Homogeneous products and services would compete in the JD platform.

JD had competed with other enterprises. JD provides self-sale products on the platform and constructed its own logistics and financial systems, which compete with other homogeneous enterprises or homogeneous products and services in the ecosystem. The competition prompted the difference in production and constantly improved the quality of products and services between enterprises, reduced the costs of production and transaction, also promoted the ecosystem evolution, so as to improve the competitiveness of the ecosystem. The competition and cooperation among enterprises in the JD ecosystem have led to the formation of JD eco-advantages.

The species in the ecosystem were in different Niches (Barve et al., 2001), and they were symbiotic in an ecological network (Hart et al., 2013; Oteros-Rozas et al., 2014). As shown in Figure 2, the species in the platform ecosystem are divided into different grades according to their function and niche of the species. Platform leader is the leading species which play a core platform role in the ecosystem; demand and supply sides were users of the platform. Suppliers included manufacturers, buyers, suppliers, and distributors who were the traditional value chain. Those users included terminal demand, organizations, and enterprises. The nodes in the ecosystem are connected with each other, forming a symbiosis, interdependence, and competition environment and formed a complex value network (Hambrick et al., 2015; Silver et al., 2016).

JD was a platform connecting all types of enterprises and consumers in the ecosystem. JD was the core of the ecosystem and determines the development and competition vitality of the ecosystem. Other species were the complement that gathered in the ecosystem for the JD platform. All species in the ecosystem had formed a huge value network through the JD platform, such as capital flow, 


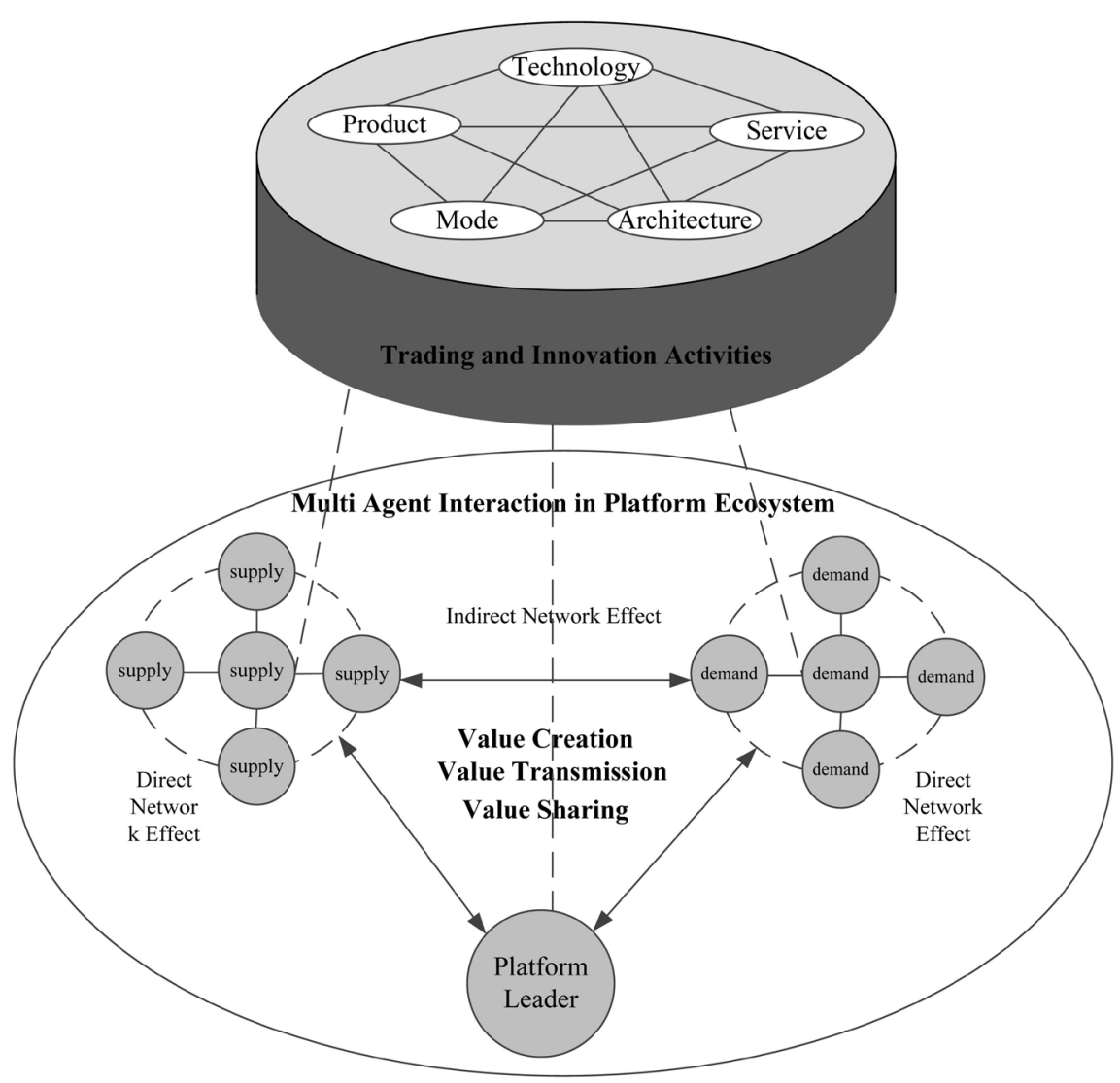

Figure 2. Value network of ecosystem.

logistics, technology flow, the flow of people, information flow, and so on. In the value network, there are various types and different functions of species, such as household appliances, mobile phones, computers, baby clothes, finance, cloud computing, delivery, insurance and other services, manufacturing, storage, transport, and the decomposition of consumption. Those enterprises were in different niches, playing different functions and roles, forming a symbiotic relationship, and maintaining the virtuous circle of the whole value network.

Proposition 3: Ecosystem is a value network that consisted of many firm nodes that were symbiotic and interdependent by coopetition and reciprocity. The cross-border integration and synergetic development of multi-agent in the ecosystem are conducive to promoting the platform leading enterprises to form ecological advantages and achieve sustainable development.

\subsection{Value Co-Creation Based on Platform}

The platform firm which plays a leader role connected with the supply side and demand side and other species in the ecosystem (Adner, 2017), provided infrastructure equipment for enterprises to online transact and saved searching time to improve transaction efficiency and reduce transaction costs. It also produced the interacted and cooperated with enterprises in the ecosystem, and cooperated create value (Vargo, Maglio, \& Akaka, 2008). 
There were many different species in the ecosystem, each of which has different interests (Schreiber \& Gutierrez, 1998). Demand-side collected information through the platform to make purchase decisions and then received the goods through the logistics service. In this process, the demand side wanted to get the services including information collection, commodity information, commodity quality control and assurance, delivery tracking, supervision experience feedback, and correction on the platform. And the platform can provide services for suppliers, mainly including the analysis of user search behavior and potential demand, collection of user data and information, processing user order, providing accurate information for the supply and marketing demand, justice of contract breach, reduce transaction costs and improve transaction efficiency (Adner, 2017; Bellamy et al., 2014; Gawer \& Cusumano, 2014). The supporting system, such as logistics and financial services, played an important role in exchanges between the supply and demand.

Business activity is the interaction of many firms on the platform based on the leader enterprise (Prahalad \& Ramaswamy, 2004). The process of the eco-advantage was modularized decomposition and collaboration according to the process of value creation (Tiwana, 2015).

Three modules business including e-commerce, finance, and logistics in the JD platform, and the value creation and distribution logic between them were shown in Figure 3. The e-commerce platform module is composed of hardware, software, services, and rules, including the JD cloud which involved in cloud computing, big data, smart logistics, artificial intelligence, AR/VR, intelligent hardware technology. Those were the foundation of the technology-driven and

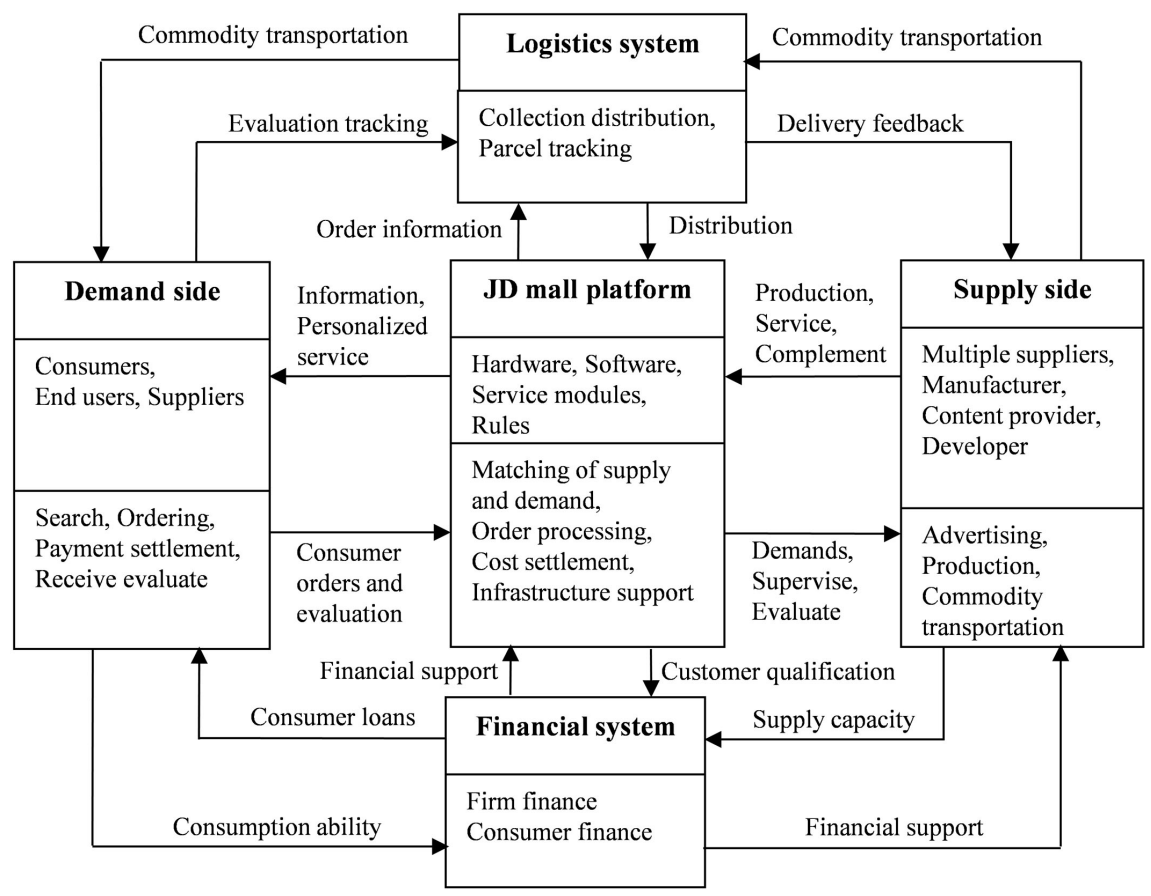

Figure 3. Business module value creational and distributional logic of JD. 
were the core technologies of smart business. The function of this module was to provide the basic technical support for the demand side, supply side, logistics system, and financial system module, so that participants can share information, safeguard the rights and interests of all parties, and supervise all parties to fulfill their obligations. Specific functions included providing information on search and personalized service for the demand side, the user needs information for the supplier, and provides supervision and evaluation of the user, provides order information for the logistics system, provides the user's qualification and information for the financial system. The financial module, which based on a technology platform to create a credit system based on transaction records, had established nine business segments, including supply chain finance, consumer finance, chips, wealth management, payment, insurance, securities, financial technology, and rural finance. This module not only provided consumers with JD IOUs and installment forms of consumer lending, financing, payment, but also provided the chips, financing, payment, financial and other services to sellers and entrepreneurs. Logistics module which based on the technology platform provided forward and reverses integration services for transport, warehousing, distribution, customer service the supplier, customer service, and constructed six cross-border logistics networks including large packets medium and small packets, cold chain, B2B, and others. The logistics module also provided express tracking service, feedback of consumer comments for consumers. The goal of the JD logistics module was to build a supply chain service network system through scientific and technological innovation, focus on improving the efficiency of circulation, reduce supply chain costs, and provide satisfactory customer experience from analysis and forecasting of product sales to the storage, transportation, and distribution.

The resources and capacity of leader enterprise were limited, so the sustainable competitive advantage was challenged, but the ecosystem blurs the boundaries of the enterprise, and external enterprise could be increased (Gawer \& Cusumano, 2014), so a large number of external enterprises to enter the platform as a supplement to achieve complementary advantages between outside enterprises and platform enterprises (Boudreau \& Jeppesen, 2015). In the orientation of user demand-driven, platform enterprises which played a leading role in the ecosystem integrated the external resources and capacities, participated in the value creation activities, to produce high value-added products and services and achieve accurate matching of supply and demand (Kale et al., 2002). This process was the open innovation activities that the leader enterprises make use of external resources and capabilities which increased along with the expansion of the ecosystem (Figure 4).

JD was an open innovation ecosystem constructed together by suppliers, customers, third parties, co-authors, and itself. JD was an e-commerce company, had support infrastructures, equipment, user demands information, financial and logistics support system for e-commerce development. The innovation of JD focus on business models, infrastructure and key technologies, and combined 


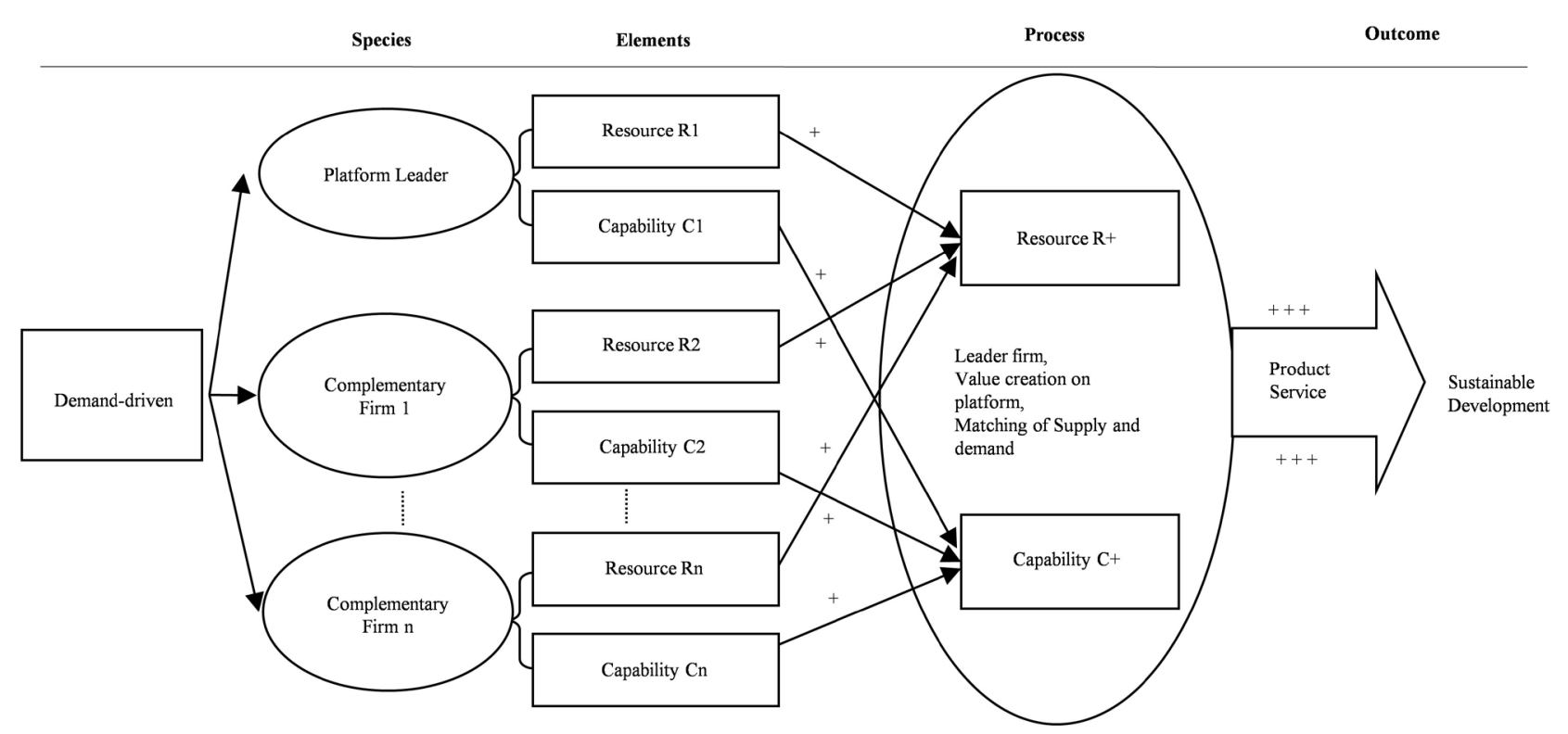

Figure 4. The eco-advantages of the core enterprises in ecosystem.

with other species in the ecosystem to cooperate, constantly enrich and expand the ecosystem members, inhalant resources, develop new markets, open innovation, promote the renewal and reconstruction of the value network, and promote the development of the ecosystem. Therefore, the formation of JD eco-advantages comes from both internal innovation and external open innovation. Both internal and external complement each other to promote the sustainable development for platform leader. Nowadays, the products and services provided by JD have been completed by thousands of enterprises, involving many enterprises and across many industries. A commodity may consist of several components, each of which may come from different manufacturers. Those, who came from different industries and enterprises which Owen different resources and production capacity, constitute a large network of value creation under the leadership of the JD. The scale and content continue to expand with the increasing number of users richer.

Proposition 4: Platform firm was the leader and key species in the ecosystem, it was of vital importance for the whole ecosystem and species, the leader enterprise to provide a platform for lots firms to create value, and the formation of the eco-advantages and sustainable development of the platform leaders in the process of multi-agent value co-creation based on platform, and also the result of internal innovation and external open innovation.

\section{Conclusions and Implications}

\subsection{Conclusion}

Business paradigm has changed that it's not only the individual enterprise's competitions, supply chain, and value chain competitions, but also the competitions between business ecosystems based on the leading leader in the back- 
ground of the development of the Internet, artificial intelligence, big data, cloud computing, and other modern information technology. Competitive advantages that relied on enterprise internal resources have been replaced by eco-advantages that dependent on platform and external network which consist of numerous customers, suppliers, and complementors.

The operation and development of enterprises were influenced by not only the internal resources and capabilities but also the external environment, so the establishment of the business ecosystem is the strategic choice for many enterprises. The eco-advantages of the platform enterprises are formed in the ecosystem, and the ecological advantages must be linked with the ecosystem. The business ecosystem not only paid attention to its heterogeneity of competitive advantages and resources but also emphasized the interdependence, complementarity, cross-border innovation, coexistence, and win-win in the ecosystem.

The business ecosystem could change the linear model of the enterprise's value chain, reduce some intermediate sectors, and transfer process to speed up the flow of transactions, overcome the information asymmetry between supply and demand. The business ecosystem can achieve large-scale collaboration and diversity of customized products, as it owns a strong ability of cross-border integration, decomposition and combination of value module, which could reduce the production cost, and also meet individual needs $f$ varieties consumers. The business ecosystem can also help enterprises to adapt to the external environment quickly and effectively, and deal with risks and hidden dangers caused by unstable factors to not be eliminated in the fierce market competition.

This paper researched the path and principle of platform leader's sustainable development in the platform ecosystem based on the theory of population ecology and ecosystem. The basic conclusions are as follows: Firstly, the platform enterprise is the leading species and building group species of the platform-based business ecosystem, which is related to the life and death of the whole ecosystem. The realization of sustainable development for platform leaders mainly includes four aspects: user base, multi-agent value co-creation based on platform, stimulation of network effect, and complementary symbiosis of ecosystem network nodes. The sustainable development of platform leader needs a large number of users with good quality; the process of sustainable development is also the process of multi-agent value co-creation based on the platform; the stimulation of network effect is the key to the formation of eco-advantages and the realization of sustainable development, and its scale and intensity determine the strength of ecological advantages; the complementary symbiosis between node enterprises in the ecosystem, other species are the important supplement and support for the ecological advantages of core enterprises.

Secondly, the formation path of sustainable development for platform leaders mainly includes internal and external path, ecological network path, online and offline path, modularization. The ecosystem is an open, innovative, and symbiotic complex composed of multiple species. The internal and external superior 
resources and capabilities of core enterprises jointly are beneficial to the promotion of eco-advantages; the ecosystem value network provides the best path for the formation of sustainable development for platform leader; online convenience and offline scene experience integrated with virtual reality, and the modular decomposition, coordination, and optimization of the ecosystem together promote platform leader's sustainable development.

Thirdly, the sustainable development mechanism of the platform leader mainly includes demand-driven mechanisms, species competition, and cooperation mechanisms and power dependence mechanisms. The demand-driven by users is the driving mechanism of sustainable development for platform leaders; species competition and cooperation in the ecosystem promote the sustainability of ecological advantages, and the power dependence among species in the ecosystem contributes to the stability of ecological advantages.

The main contributions of this study are as follows: First, it promoted the development of eco-advantage theory, and enrich the theory of competitive advantage and organizational ecology. The competitive advantage of enterprises emphasized the internal resources and abilities to form the supply side advantage, but eco-advantage focuses on the user demands and customer orientation, leveraging external resources and capabilities by platform strategy and value network of the ecosystem. The concept of eco-advantages is the further development and expansion based on competitive advantage theory under the circumstance of a complex competitive environment. Second, it revealed the sustainable development principle of platform leader in the platform ecosystem. This paper analyzed the relationships between the key species (platform leader) and other species (complimentary) learn from population ecology, exploring the sustainable development path and mechanism of platform leading enterprises by extracting the key behavior and event. It is beneficial to help people to better understand the essence of platform transformation and ecosystem strategy. Third, the revelation of the sustainable development principle of platform leader is beneficial to enrich and perfect the research of platform theory and promote the development of theory and practice of the business ecosystem. The platform leader is the core enterprise in the platform ecosystem, it is helpful to guide the core enterprise's platform transformation and construction of the ecosystem, and to guide the enterprise to get an advantage in competition.

\subsection{Management Revelation}

This paper also put forward some suggestions for the construction of the business ecosystem and achieving sustainable development for platform leaders according to the conclusion. First, make the platform leader stronger and more powerful to construct the business ecosystem. The platform ecosystem can't do survival without the leader business, and the platform leader leverages the resources from the external firms in the ecosystem. So the platform firm should keep strong to play its edificators role and platform function, build and improve 
the business ecosystem. Second, expand the user base and at the same time be strict in control the quality of entry suppliers. The number and quality of platform users are related to the survival of the platform ecosystem. It could take a series of concessions or free activities to attract customer entry into the platform ecosystem, and make platform rules to control the quality, to promote the healthy development of the ecosystem. Third, activate the network effect and make open innovation. The network effect is a double-edged sword, on the one hand, it can get more economic value through open innovation, set the market entry barriers that could reduce the threat of external competition and strengthen the eco-advantages of the leading enterprise, but on the other hand may lead to vicious competition to gain market share. Therefore, it is necessary to take appropriate measures to control the openness of the platform ecosystem in different stages of development. Forth, establish an ecological governance mechanism. It is necessary to perfect the benefit-sharing mechanism for species, establish a formation of the fate community which could co-create, share, win-win. And deal with the relationship between competition and cooperation, balance the different stakeholders. Fifth, establish the mechanism of survival of the fittest, promote the evolution of ecosystem species, maintain ecosystem health and sustainable development, improve the competitiveness of the platform-based ecosystem.

\subsection{Limitations and Future Research}

Some limitations of this study may suggest directions for future research. Firstly, the theoretical construction and case analysis of this paper mainly focuses on the vertical analysis of a single case of JD. Whether the development strategy and its successful mode of JD can become the sample of other enterprises' imitation still needs to be further tested; Secondly, Internet leading enterprises (such as Alibaba, Tencent, JD, etc.) can quickly expand the scale of users with network effects, so the user base is large enough and it is easier for enterprises to implement the ecosystem strategy to share customers resources in multiple businesses. However, the regional barriers and policy barriers of traditional industries are different, it may not be able to gather a large number of users, and the implementation of ecosystem strategy may not produce synergy effect at the user end, so how leader firm take the ecosystem strategy needs to consider the industry attributes, and further theoretical analysis and large sample investigation are needed; Thirdly, can leader enterprises that do not directly contact consumers to produce intermediate products also adopt the ecosystem strategy? Are the ecological advantages based on the demand-side equally effective? The internal organizational structure, human resources, corporate culture, and other management modes of the ecological organization with platform leader as the core are quite different from those of traditional enterprises. What are the unique organizational genes of this leader firms, whether all aspects of the management of the enterprises implementing the ecosystem strategy need to be reconstructed, and the governance of the ecosystem needs to be further studied? 


\section{Conflicts of Interest}

The authors declare no conflicts of interest regarding the publication of this paper.

\section{References}

Adner, R. (2002). When Are Technologies Disruptive: A Demand-Based View of the Emergence of Competition. Strategic Management Journal, 8, 667-688. https://doi.org/10.1002/smj.246

Adner, R. (2017). Ecosystem as Structure: An Actionable Construct for Strategy. Journal of Management, 1, 39-58. https://doi.org/10.1177/0149206316678451

Barve, N., Barve, V., Jimenezvalverde, A., Liranoriega, A., Maher, S. P., Peterson, A. T., Villalobos, F. et al. (2011). The Crucial Role of the Accessible Area in Ecological Niche Modeling and Species Distribution Modeling. Ecological Modelling, 11, 1810-1819. https://doi.org/10.1016/j.ecolmodel.2011.02.011

Bellamy, M. A., Ghosh, S., \& Hora, M. (2014). The Influence of Supply Network Structure on Firm Innovation. Journal of Operations Management, 6, 357-373.

https://doi.org/10.1016/j.jom.2014.06.004

Bengtsson, M., \& Kock, S. (1999). Cooperation and Competition in Relationships between Competitors in Business Networks. Journal of Business \& Industrial Marketing, 3, 178-193. https://doi.org/10.1108/08858629910272184

Benson, A. R., Gleich, D. F., \& Leskovec, J. (2016). Higher-Order Organization of Complex Networks. Science, 6295, 163-166. https://doi.org/10.1126/science.aad9029

Boudreau, K. J., \& Jeppesen, L. B. (2015). Unpaid Crowd Complementors: The Platform Network Effect Mirage. Strategic Management Journal, 12, 1761-1777. https://doi.org/10.1002/smj.2324

Bouncken, R. B., \& Fredrich, V. (2016). Learning in Coopetition: Alliance Orientation, Network Size, and Firm Types. Journal of Business Research, 5, 1753-1758.

https://doi.org/10.1016/j.jbusres.2015.10.050

Eisenhardt, K. M. (1989). Building Theories from Case Study Research. Academy of Management Review, 4, 532-550. https://doi.org/10.5465/amr.1989.4308385

Eisenmann, T., Parker, G., \& Van Alstyne, M. (2011). Platform Envelopment. Strategic Management Journal, 12, 1270-1285. https://doi.org/10.1002/smj.935

Enkel, E., \& Heil, S. (2014). Preparing for Distant Collaboration: Antecedents to Potential Absorptive Capacity in Cross-industry Innovation. Technovation, 4, 242-260. https://doi.org/10.1016/j.technovation.2014.01.010

Falk, A., \& Fischbacher, U. (2006). A Theory of Reciprocity. Games and Economic Behavior, 2, 293-315. https://doi.org/10.1016/j.geb.2005.03.001

Gawer, A., \& Cusumano, M. A. (2014). Industry Platforms and Ecosystem Innovation. Journal of Product Innovation Management, 3, 417-433. https://doi.org/10.1111/jpim.12105

Grant, R. M. (1991). The Resource-Based Theory of Competitive Advantage: Implications for Strategy Formulation. California Management Review, 3, 114-135. https://doi.org/10.2307/41166664

Hambrick, D. C., Humphrey, S. E., \& Gupta, A. (2015). Structural Interdependence within Top Management Teams: A Key Moderator of Upper Echelons Predictions. Strategic Management Journal, 3, 449-461. https://doi.org/10.1002/smj.2230

Hannan, M. T., \& Freeman, J. A. (1977). The Population Ecology of Organizations. 
American Journal of Sociology, 5, 929-964. https://doi.org/10.1086/226424

Hart, M. M., Forsythe, J., Oshowski, B., Bucking, H., Jansa, J., \& Kiers, E. T. (2013). Hiding in a Crowd-Does Diversity Facilitate Persistence of a Low-Quality Fungal Partner in the Mycorrhizal Symbiosis? Symbiosis, 1, 47-56. https://doi.org/10.1007/s13199-012-0197-8

Kale, P., Dyer, J. H., \& Singh, H. (2002). Alliance Capability, Stock Market Response, and Long-Term Alliance Success: The Role of the Alliance Function. Strategic Management Journal, 8, 747-767. https://doi.org/10.1002/smj.248

Makadok, R. (2001). Toward a Synthesis of the Resource-Based and Dynamic-Capability Views of Rent Creation. Strategic Management Journal, 5, 387-401. https://doi.org/10.1002/smj.158

McIntyre, D. P., \& Srinivasan, A. (2017). Networks, Platforms, and Strategy: Emerging Views and Next Steps. Strategic Management Journal, 1, 141-160. https://doi.org/10.1002/smj.2596

Moore, J. F. (1993). Predators and Prey: A New Ecology of Competition. Harvard Business Review, 3, 75-83.

Oteros-Rozas, E., Martinlopez, B., Gonzalez, J. A., Plieninger, T., Lopez, C. A., \& Montes, C. (2014). Socio-Cultural Valuation of Ecosystem Services in a Transhumance Social-Ecological Network. Regional Environmental Change, 4, 1269-1289. https://doi.org/10.1007/s10113-013-0571-y

Prahalad, C. K., \& Ramaswamy, V. (2004). Co-Creation Experiences: The Next Practice in Value Creation. Journal of Interactive Marketing, 3, 5-14. https://doi.org/10.1002/dir.20015

Schreiber, S. J., \& Gutierrez, A. P. (1998). A Supply/Demand Perspective of Species Invasions and Coexistence: Applications to Biological Control. Ecological Modelling, 1, 27-45. https://doi.org/10.1016/S0304-3800(97)00178-6

Siggelkow, N. (2007). Persuasion with Case Studies. Academy of Management Journal, 1, 20-24. https://doi.org/10.5465/amj.2007.24160882

Silver, D., Huang, A., Maddison, C. J., Guez, A., Sifre, L., Den Driessche, G. V., Hassabis, D. et al. (2016). Mastering the Game of Go with Deep Neural Networks and Tree Search. Nature, 7587, 484-489. https://doi.org/10.1038/nature16961

Tiwana, A. (2015). Platform Desertion by App Developers. Journal of Management Information Systems, 4, 40-77. https://doi.org/10.1080/07421222.2015.1138365

Van de Ven, A. H. (2007). Engaged Scholarship: A Guide for Organizational and Social Research. Oxford: Oxford University Press.

Vargo, S. L., Maglio, P. P., \& Akaka, M. A. (2008). On Value and Value Co-Creation: A Service Systems and Service Logic Perspective. European Management Journal, 3, 145-152. https://doi.org/10.1016/j.emj.2008.04.003

Wernerfelt, B. (1984). A Resource-Based View of the Firm. Strategic Management Journal, 2, 171-180. https://doi.org/10.1002/smj.4250050207

Yin, R. K. (2009). Case Study Research: Design and Methods (4th ed.). Los Angeles, CA: SAGE.

Zhu, F., \& Iansiti, M. (2012). Entry into Platform-Based Markets. Strategic Management Journal, 1, 88-106. https://doi.org/10.1002/smj.941 